\title{
ORIGEN Y EVOLUCIÓN DEL TÉRMINO GUAJIRO
}

\author{
Juan Carlos Rodríguez Cruzl \\ Luiz Bezerra Neto² \\ Carlos Antonio Córdova Martínez 3
}

\section{RESUMEN}

El texto discute los principales aspectos de la familia lingüística arahuaca, una lengua que según Bartolomé de Las Casas con sus muchas variantes era ampliamente hablada en toda América cuando la llegada de los españoles en ese territorio, sobre todo, en el área en que se sitúa hoy, el territorio Cubano, aunque se extiende desde el sur hasta el norte de América. Destacamos el hecho de que tanto las lenguas castellanas y otras lenguas aquí utilizadas se apropiaron de muchas palabras de las lenguas indígenas, sobre todo las de tronco Arawak, como ejemplo, tenemos la palabra Guajiro cuyo significado designa una posición social que significa cacique en Tierra Firme. Las contribuciones de las lenguas indigenas en la formación de palabras y nombres de nuestra flora y faunas son enormes, así que traemos un poco de estas contribuciones, sobre todo para comprender su importancia para el campesinado en América Latina. Además, destacamos el sonido de algunos prefijos de palabras como "gua" que teniendo orígenes diferentes es usada frecuentemente en América Latina o África del Norte.

Palabras clave: Lengua arahuaca. Contribución de las lenguas indígenas. Formación de palabras.

\section{ORIGEM E EVOLUÇÃO DO TERMO GUAJIRO}

\section{RESUMO}

O texto discute os principais aspectos da família linguística arahuaca, uma língua que segundo Bartolomeu de Las Casas com suas muitas variantes era amplamente falada em toda a América quando da chegada dos espanhóis nesse território, sobretudo, na área em que se situa hoje, o território cubano, embora se espalhe desde o sul até o norte da América. Destacamos o fato de que tanto as línguas castelhanas quanto outras línguas aqui utilizadas se apropriaram de muitas palavras das línguas indígenas, sobretudo as de tronco Arawak, como exemplo, temos a palavra Guajiro cujo significado designa uma posição social que significa cacique

\footnotetext{
1 Doutor pela Universidade de Cuba. E-mail: jcrodriguez@fh.uho.edu.cu

2 Doutor em Educação pela Universidade Estadual de Campinas, pós-doutor pela Universidade Federal da Bahia - UFBA. Professor da Universidade Federal de São Carlos atuando na graduação e na pós-graduação. E-mail: Ibezerra@ufscar.com.br

3 Doctor en Ciencias Filosóficas. Primer Profesor Titular de la Universidad de Ciencias Pedagógicas José de la Luz y Caballero de Holguín.
}

Revista Exitus, Santarém/PA, Vol. 7, N³, p. 427-440, Set/Dez 2017. 
em Tierra Firme. As contribuições das línguas indigenas na formação de palavras e nomes da nossa flora e faunas são enormes, assim, trazemos um pouco destas contribuições, sobretudo para compreendermos sua importância para o campesinato na América Latina. Além disso, destacamos o som de alguns prefixos de palavras como "gua" que tendo origens diferentes é usada frequentemente na América Latina ou África do Norte.

Palavras chave: Língua arahuaca. Contribuição das línguas indígenas. Formação de palavras.

\section{ORIGEN Y EVOLUCIÓN DEL END GUAJIRO}

\section{ABSTRACT}

The paper discusses the key aspects of the arahuaca language family, a language which according to Bartholomew de Las Casas with its many variants was widely spoken across America when the arrival of the Spaniards in the territory, especially in the area where today the Cuban territory, although they spread from the South to the North of America. We highlight the fact that both the Castilian languages as other languages here used have appropriated many words of indigenous languages, especially the Arawak trunk, as an example, we have the word Guajiro which designates a social position that means Chief in Tierra Firme. The contributions of indigenous languages in the formation of words and names of our flora and fauna are huge, so bring some of these contributions, especially to understand your importance to the peasantry in Latin America. In addition, we feature the sound of some prefixes of words like "gua" having different origins is often used in Latin America or North Africa.

Keywords: Arahuaca Language. Contribution of indigenous languages. Formation of words.

\section{INTRODUCCIÓN}

Los españoles a su llegada a América encontraron, que los indígenas americanos, se expresaban en muy diversas lenguas; no obstante su primer encuentro tuvo lugar con la familia lingüística arahuaca, dominante en el territorio de las Antillas y zonas del norte de América del Sur. En Cuba, La Española, Jamaica, Puerto Rico y las Bahamas se hablaban variantes de la lengua arahuaca antillana, que era la lengua principal en la región a la llegada de los europeos.

De Las Casas en su Historia de las Indias, hace una distribución de las variantes lingüísticas arahuaca por zonas o asentamientos. Considera que el taíno clásico, se hablaba en la región oriental de Cuba y la mayor parte de 
La Española. Éste tenía a su vez diferentes variantes regionales, de las cuales el taíno del cacicazgo de Jaraguá se consideraba el más elegante y prestigioso que sirvió como segunda lengua por los hablantes de otras lenguas de la región, así como lingua franca del comercio y la cultura. Según De las Casas era una lengua que casi todos conocían y podían entender, aunque claramente coexistía con otras lenguas en las Antillas mayores. Respecto al taíno siboney, era la lengua hablada en el extremo sur occidental de La Española, la mayor parte de Cuba oriental y central y probablemente Jamaica. ${ }^{4}$

De las lenguas pertenecientes al tronco arahuaco han pasado varios préstamos de palabras al castellano y a otros idiomas, como por ejemplo los siguientes términos: ácana, guácima, guayaba, hicaco, mamey, biajaca, caimán, guacamayo barbacoa, bohío, caney, canoa, conuco, cacique, cemí, cayo, huracán, 5 por solo citar algunos. Relacionado con lo anterior se encuentra el vocablo guajiro, objeto de análisis en este artículo, que por su larga trayectoria cultural, es digno de un análisis pormenorizado; este trabajo tiene como fin valorar el origen y evolución del término guajiro.

El texto discute los principales aspectos de la familia lingüística arahuaca, con sus muchas variantes en toda América cuando la llegada de los españoles en ese territorio, sobre todo, en el área en que se sitúa hoy, el territorio Cubano. Bien como a apropiaron de muchas palabras de las lenguas indígenas, sobre todo las de tronco Arawak, por el lenguas castelhanas, asi como as contribuciones de las lenguas indigenas en la formación de palabras y nombres de nuestra flora y faunas son enormes, así que traemos un poco de estas contribuciones, sobre todo para comprender su importancia para el campesinado en América Latina.

\footnotetext{
4 Bartolomé de las Casas: Historia de las Indias. Editor M. Aguilar. Madrid, 1927, vol. 1, cap. LXVII

5 Sergio O. Valdés Bernal: La hispanización de América y la americanización de la lengua española. Editorial Universidad de La Habana. la Habana, 2015. p.100.
} 


\section{DESARROLLO}

Los pueblos arahuacos que se autodenominaban taínos, hablantes de la lengua homónima, avanzaron desde el oriente de Venezuela hacia el noroeste siguiendo la cadena insular caribeña, desplazando o reduciendo a los pobladores anteriores como los guanahatabeyes en el occidente de Cuba y los ciguayos y macoríes en La Española. Es de notar que entre estos grupos existieron interconexiones lingüísticas inevitables.

Según la investigadora Nuria Gregori, prologuista del Diccionario provincial casi razonado de vozes y frases cubanas considera que su autor, Esteban Pichardo, "es el primero en América que da una explicación de la flora, fauna, producciones, industrias y describe los usos y costumbres de los naturales de una región de la A mérica hispanohablante: Cuba".6

Se toma como punto de partida lo planteado por Pichardo respecto al vocablo guajiro. Este considera en sus diferentes acepciones que guajiro es

(...) sinónimo de campesino, esto es, la persona dedicada al campo con absoluta residencia en él...sus modales son groseros, cruza las piernas sin reparo y no se quita el sombrero por nada: para él no hay mal tiempo, ni malos caminos, ni necesidades; sobrio, se contenta con poca comida, frutas, lo que haya, con tal que no le falte el tabaco, una taza de café mal hecho y alguna pelea de gallos, franco, generoso, todo lo da, todo lo gasta o lo juega... indómito, vengativo y celoso a la más ligera ofensa, a la chanza más discreta, pela por el quimbo de una manera brutal, implacable, sin reparar en número, categorías y circunstancias... este es el guajiro, el hombre peculiar de la Isla de Cuba, que bien merece ser descrito con alguna extensión. En la Vuelta Arriba dicen también montuno y algunos en Cuba jíbaro como en Puerto Rico."7

El investigador Pichardo caracteriza al guajiro de forma psicológica. En esta caracterización puntualiza sus modos de actuar o pensar; pero no analiza y expone críticamente el origen etimológico del término guajiro, ni el por qué de su designación al campesino cubano.

\footnotetext{
$6 \quad$ Nuria Gregori: En prólogo al Diccionario provincial casi razonado de vozes y frases cubanas de Esteban Pichardo. Editorial de Ciencias Sociales, La Habana, 1985.

$7 \quad$ Esteban Pichardo: Diccionario provincial casi razonado de vozes y frases cubanas de Esteban Pichardo. Editorial de Ciencias Sociales, La Habana, 1985. p.295-297.
} 
El diccionario de la Academia, según Fernando Ortiz, dice que "es el campesino blanco de la Isla de Cuba, ya rectificado por dicho diccionario" 8 . Señala Ortiz que "el guajiro era blanco, porque el negro era esclavo, pero en la medida que el negro se ha emancipado, también la gente de color se ha hecho guajira." 9

Según el Sr. Noda, citado por Bachiller, guajiro era el significado de la palabra que designaba un rango social inferior al de cacique y lo aplica a los naturales de Vueltabajo y, Fernando de Oviedo, cronista del siglo XVI, citado también por Bachiller, considera que es sinónimo de cacique en Tierra Firme. 10 Según Oviedo "esta palabra la han adoptado de los caribes" 11 ..."los guahiros o goagiros me parecen tribus de la bella nación caribe". ${ }^{12}$

Además, señala Bachiller, que si gua es artículo, tal vez parezca compuesta la palabra guajiro de gua y gíbaro'3 y ejemplifica con las expresiones "perros gíbaros y cochinos gíbaros. Con estas expresiones llaman en Cuba a los silvestres y gíbaro al campesino de Puerto Rico." 14

El término, gua, según Pedro Mártir de Anglería, el cronista de Indias, "en las lenguas de las Antillas es un artículo demostrativo y que puede entenderse como: tal, este, aquello, estos, esos"15; y Bachiller considera que "en lengua goagira significa nuestro"16. Lo que no puede suceder es confundir el vocablo gua con agua porque según dice Bachiller "el Sr. de la

\footnotetext{
8 Fernando Ortiz: Nuevo Catauro de Cubanismos. Editorial de Ciencias Sociales, La Habana, 1974. p.273-274.

$9 \quad$ Idem. p.273-274

10 Antonio Bachiller y Morales: Cuba Primitiva, origen, Lenguas, Tradiciones e Historia de los Indios de las Antillas Mayores y Las Lucayas. Imprenta La Correspondencia de Cuba. 1883.p.273

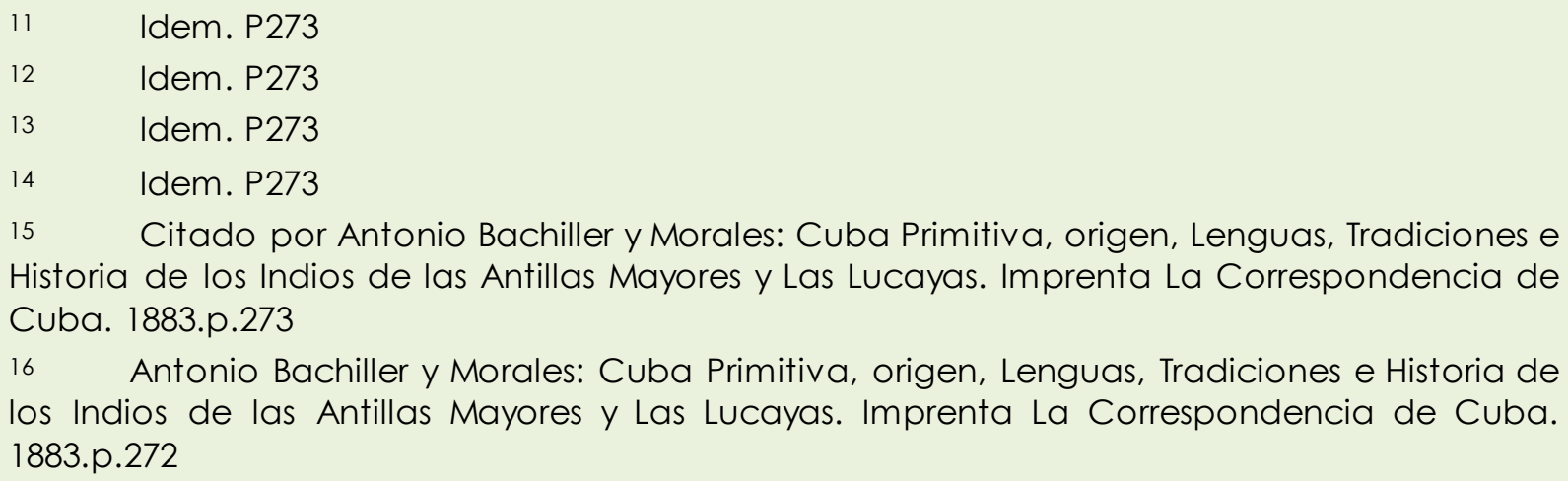


Torre observa que los indios mezclaban la palabra agua con casi todos los nombres de ríos y pueblos inmediatos." 17

En el sitio Web https://www.ecured.cu/ aparece una publicación titulada: Guajiro. Se cita textualmente lo siguiente:

Andrés Martínez Coronel, residente de Campeche, México y estudioso de la cultura cubana, destaca la información extraída de La Primera Edición Del Diccionario Moderno Taíno La Sabiduría Del Cemí, Nosotros Somos Taínos No Arahuacos que Gua = pron: $\mathbf{E l}$ o La, usado con gente de alto rango, ejemplo EL Rey o La Reina. Aquí Andrés observa la raíz probable del vocablo. (https://www.ecured.cu/Guajiro (consultado el 6 de abril de 2017)

El articulista, cuyo nombre se desconoce, no brinda comentario alguno. Pero el criterio de Martínez Coronel merece un análisis. El o La, tanto: tal, este, aquello, estos, esos, son artículos demostrativos. Si se tiene en cuenta lo anterior y se examina lo planteado por Bachiller, que en Cuba las frases perros gíbaros y cochinos gíbaros son expresiones las cuales designan en la Isla a los silvestres, pudiera pensarse que el contenido semántico del término guajiro signifique: el silvestre, este silvestre o nuestro silvestre, si en lengua goagira significa nuestro, como señala Bachiller.

Según este mismo autor, en la Sección Tercera de su libro ya citado: palabras usuales en Cuba de origen indio, sus diversas acepciones en los departamentos: vegetales, animales, ríos, pueblos, lugares yobjetos, plantea que la palabra silvestre se emplea para designar "a los animales y a los guajiros en Puerto Rico," 18 y el Padre Murillo considera que gibaros son "los criollos y mestizos de la Española, Puerto Rico y otras islas..." 19

Esteban Pichardo en su diccionario, ya citado, plantea que criollo, en sus diversas acepciones es "cualquiera cosa originaria o peculiar del país en comparación de otra exótica o ultramarina, y en este concepto es lo mismo

\footnotetext{
$17 \quad$ Idem. p.189

18 Antonio Bachiller y Morales: Cuba Primitiva, origen, Lenguas, Tradiciones e Historia de los Indios de las Antillas Mayores y Las Lucayas. Imprenta La Correspondencia de Cuba. 1883. p.367.

19 Citado por Antonio Bachiller y Morales: Cuba Primitiva, origen, Lenguas, Tradiciones e Historia de los Indios de las Antillas Mayores y Las Lucayas. Imprenta La Correspondencia de Cuba. 1883. p.310.
} 
que decir de la Tierra/ por excelencia la persona blanca nacida en el país con relación a la Europea, y el Negro nacido aquí de padres A fricanos..."20

Lo planteado por el Padre Murillo respecto a la designación de gibaros en La Española, Puerto Rico y otras islas, como pudiera ser Cuba, y lo sostenido por Pichardo, permite suponer que guajiro pudiera significar en lengua castellana el criollo, el mestizo, nuestro criollo o nuestro mestizo.

El sabio cubano Fernando Ortiz en su Nuevo Catauro de Cubanismos señala que "...Nuestro nombre de guajiro puede pues, haberse tomado de los indios esclavizados que en el siglo XVI se trajeron a Cuba desde Venezuela."21 Respecto a lo planteado por Ortiz, Díaz Perera, antropóloga especialista en folklore latinoamericano considera lo siguiente:

(...) me parece (y aquí hablo sin conocer, más bien usando la forma popular en que la gente adopta palabras), que si los trajeron de Venezuela para labrar la tierra y se llamaban guajiros, el referirse a ellos con esta palabra poco a poco pudo haberse diseminado o ampliado para abarcar todo aquel que ocupara su tiempo con este trabajo, no importa la raza, y que gradualmente se haya perdido la conexión con los indígenas originales. ¿Sabes cómo llaman a los campesinos entre los yucatecos? A los indios yucatecos también se les llama guajiros aparte de que el vocablo significara "Señor"? En Cuba muchas veces la palabra "guajiro" adopta un giro casi peyorativo. (https://www.ecured.cu/Guajiro, consultado el 6 de abril de 2017)

Lo sugerido por Ortiz y Díaz Perera sobre la entrada de indios a Cuba forzosamente por los españoles, puede ser una razón esencial para que algún estudioso considere que el término guajiro fuera introducido por ellos, en tanto tal, la llegada de yucatecos. El historiador Ramiro Guerra en su Manual de Historia de Cuba puntualiza que "los primeros yucatecos llegaron a Cuba alrededor de 1513 por la escasez de mano de obra, porque el colonizador exterminó muy rápido a nuestros aborígenes, por eso comenzó la práctica de "ranchear" o sea, secuestrar a los indios de las tierras vecinas

20 Esteban Pichardo: Diccionario provincial casi razonado de vozes y frases cubanas de Esteban Pichardo. Editorial de Ciencias Sociales, La Habana, 1985. p.191.

$21 \quad$ Fernando Ortiz: Nuevo Catauro de Cubanismos. Editorial de Ciencias Sociales, La Habana, 1974. p.274. 
para someterlos como esclavos." (https://www.ecured.cu/Guajiro, consultado el 6 de abril de 2017)

El planteamiento de Díaz Perera, respecto a que el referirse a ellos, los yucatecos, con esta palabra, guajiro, poco a poco pudo haberse diseminado o ampliado para abarcar todo aquel que ocupara su tiempo con este trabajo, es un supuesto sin argumentación. No se concuerda con la investigadora, pues este término posiblemente no hubiese escapado a la pluma de nuestros primeros historiadores José Martín Félix de Arrate (16971766),22 Pedro Agustín Morel de Santa Cruz e Ignacio de Urrutia y Montoya (1735-1795), los cuales no hacen alusión al término en el período que abarcan los siglos XVI, XVII y la primera mitad del Siglo XVIII. Al parecer si el término se empleó entre los yucatecos llegados a Cuba en el siglo XVI, pronto dejó de hacerlo.

A partir de lo anterior expuesto se formula la siguiente pregunta: ¿La palabra guajiro empleada en Cuba para designar al campesino tuvo el mismo origen etimológico y contenido semántico que el término guajiro, vocablo indo-antillano, conocido por los españoles en el Nuevo Mundo?

El vocablo guahiros o goagiros, según el cronista Oviedo, ya citado, es término indo-antillano, o como lo escribe Las Casas, guaoxerí23, y al corromperse la palabra comenzó a ser nombrado guajiro. Esto pudo ser la razón por la cual hoy el gentilicio de los que habitan la Península de la Guajira, situada entre el extremo nororiental de Colombia y el extremo noroccidental de Venezuela se les nombre guajiros.

No significa que el término guajiro empleado en Cuba, que es sinónimo de campesino, haya tenido el mismo contenido semántico y origen fonético que el que tuvo en esta región de La Guajira o en la zona yucateca; aun cuando muchos indios fueron traídos de la zona de Venezuela y muchos

22 José Martín Félix de Arrate: Llave del Nuevo Mundo Antemural de Las IndiasOccidentales. La Habana descrita: Noticias de su fundación, aumentos y estados. Comisión Nacional Cubana de la UNESCO. La Habana, 1964.

23 Citado en https://www.ecured.cu/Guajiro (consultado el 6 de abril de 2017) 
yucatecos hayan llegado a varias zonas del territorio cubano, en el siglo XVI y post eriormente, como señala Ramiro Guerra.

Sobre el término guajiro empleado en Cuba, como sinónimo de campesino, se realizará un análisis, desde el punto de vista etimológico. Esteban Pichardo considera que

la sílaba guá fue una sílaba común no solamente al Nuevo, sino al Antiguo Mundo, fue escrita diversamente en varias voces con las letras oa, va, hua, ova... ¿̇y por qué detenerse cuando la $w$ valona con que los ingleses expresan en ocasiones el gua ...como si fuese de origen Sajón? (Esteban Pichardo)24

Lo anterior hace suponer que en otras voces del Viejo Mundo o africanas se sustituía la w por la u.

Esto permite dilucidar que, además de las voces con las letras oa, va, hua, ova pudo haber otras formas de escribir la sílaba gua. Ortiz en su Catauro de Cubanismos señala esta sílaba de la siguiente manera: gwá, con $w, y$ dice que

\begin{abstract}
Significa ave en el lenguaje kiboma o baduna, que se habla en las riveras del Kuango, inmediato al Congo. Este fonema se convierte en gwana, según especial nota del propio Johnston entre los lúmbila...y va variando en wañga o guanga, kañga, ñgangi, ñka, ñgwali, ñguru, ñgwa, nkan, gañ, hañga y gañga, significando concretamente gallina de guinea...Entre los yolofes, guanare es ave y también gallina."25 Señala también Ortiz que "probablemente, esa raíz gwá es de origen onomatopéyico, y ello explica su extensión; hasta entre los negros más septentrionales de los que llegaron esclavos..." 26
\end{abstract}

Otras palabras como guateque y guataca, que también llevan la sílaba gua, esta sílaba no precisa del mismo origen fonético, aunque se escriba de igual forma. Ortiz señala que, en guateque: "Armas dice que tal vez se deriva del arábigo huad, mano, porque es baile de la gentualla en que se suele llevar el compás de la mano." 27 Y respecto a guataca, Armas

$24 \quad$ Esteban Pichardo: Diccionario provincial casi razonado de vozes y frases cubanas de Esteban Pichardo. Editorial de Ciencias Sociales, La Habana, 1985. p.20

25 Fernando Ortiz: Nuevo Catauro de Cubanismos. Editorial de Ciencias Sociales, La Habana, 1974. p.275.

26 Idem. p.276.

$27 \quad$ Idem. p.279. 
señala: "...de huad, mano, explica esta acepción de adular, que también se dice en Cuba pasar la mano." 28

Por tanto, el sonido gua que ha llegado hasta la actualidad tiene diverso origen $y$, no precisamente, una palabra de uso frecuente en Iberoamérica o África septentrional, que lleve esta raíz, obligue a pensar que es de origen indo-antillano.

Si el vocablo gwá, según Ortiz significa ave, puede inferirse que la palabra guajiro, signifique ave criolla, si se tiene en cuenta que jíbaro, significa criollo, según el Padre Murillo, citado por Bachiller. Por tanto, hasta ahora, se tienen diferentes acepciones significativas de la palabra guajiro, como son: el silvestre, este silvestre o nuestro silvestre; el criollo, el mestizo, nuestro criollo, nuestro mestizo; ave criolla, ave silvestre, gallina criolla o gallina silvestre.

La historiografía puede esclarecer un tanto sobre el concepto criollo. Torres Cuevas precisa que

El concepto criollo se aplicó a los naturales de la Isla desde el propio siglo XVI. Por ello, los identificaba, definía y unía más allá de los factores étnicos, raciales, religiosos o de origen de sus padres. Se le llamaba peninsular al español que llegaba desde Europa y criollo al nacido aquí; bosal al africano y criollo al negro nacido en la Isla. Los criollos (palabra que significa el pollo criado en casa para diferenciarlo del otro, del que viene desde afuera... 29

Existe gran similitud entre el significado de criollo, dado por la historiografía cubana, como: pollo criado en casa, y el de guajiro, dado por estos investigadores, como: ave criolla o gallina criolla, que es también criada en casa, si se analiza que criollo significa nacido aquí, como señala el referido historiador.

A partir de lo explicitado se formula una pregunta: ¿̇En qué momento de la historia de Cuba se comienza a designar guajiro al campesino cubano?

\footnotetext{
28 Idem. p.279.

29 Eduardo Torres Cuevas: Historia de Cuba 1492-1898. Formación y liberación de la nación. Editorial Pueblo y Educación. La Habana, 2001. p.85.
} 
Entre los vocablos criollo y guajiro la diferencia de contenido semántico es mínima. La diferencia mayor se encuentra en el estatus social que alcanzara la persona, la cultura y riqueza que se creara y el lugar de residencia.

El historiador Félix de Arrate, cita lo planteado por el Marqués de Altamira: "Los criollos logran gentileza en los cuerpos, belleza en las caras, afable trato, discreción y mucha urbanidad." 30 Es indudable que Altamira se refiere esencialmente a las personas de la clase culta de la aristocracia cubana que vivían en La Habana. Mientras todo aquel que marchó al monte como un ave y vivió como un jíbaro (silvestre) se les llamó guajiros, es decir ave silvestre. Lo anterior lo corrobora el Dr. Dario Espina Pérez en su Diccionario de cubanismos refiriéndose al vocablo guajiro cuando dice: "... aplícase al cubano que no es de La Habana." 31

En la búsqueda realizada por estos investigadores no se ha encontrado referencia alguna, ni en la historiografía ni en la literatura, en el período comprendido entre los siglos XVII y la primera mitad del XVIII, del vocablo guajiro. Es de suponer que en la segunda mitad del siglo XVIII es que el término guajiro comienza a aplicarse al hombre del campo, cuyas características culturales y psicológicas son producto de la evolución desde los primeros siglos de la Colonia.

Esteban Pichardo recoge el término guajiro en su Diccionario provincial casi razonado de vozes y frases cubanas, que tiene su primera publicación en 1836; y se encuentra generalizado en la literatura del siglo XIX, como reflejo de una época, al expresar el sentir del alma de un pueblo hasta en los menores detalles.

Domingo del Monte (1804-1853) en su poema El Guajiro, Romance III, dice: "Belén, la del garbo y gracia/ la más donosa guajira/ que entre las

$30 \quad$ José Martín Félix de Arrate: Llave del Nuevo Mundo Antemural de Las IndiasOccidentales. La Habana descrita: Noticias de su fundación, aumentos y estados. Comisión Nacional Cubana de la UNESCO. La Habana, 1964. p.96.

31 Citado en https://www.ecured.cu/Guajiro (consultado el 6 de abril de 2017) 
hembras de Cuba/con ojos negros hechiza."32 Francisco Pobeda y Armenteros (1796-1881) en su poema Descripción de los guajiros dice: "Para pintar al guajiro/con la mayor perfección" y, en otros versos, como: "el guajiro sabanero/ el guajiro estanciero/el guajiro mayoral/el guajiro compromete."33

Pero fue Juan Cristobal Nápoles Fajardo, (El Cucalambé), (1820-1862), el que más cerca estuvo del alma del pueblo cubano, y más aplica el término guajiro en sus versos. En el poema Galas de Cuba señala: "(...) Las guajiras que entre flores/nacen en tus campos bellos..."34 En La Primavera: "Las guajiitas hermosas/ tan sencillas como ufanas..." 35 En Amante Rendido: "Iba un guajiro montado/sobre una yegua trotona." 36 En A Rufina: "El guajiro en su bohío/canta con dúlcido afán..." 37 Y en Mi Guajira: "Cuando en los prados de mi Cuba hermosa/Mi guajira gentil llena su falda."38 Por solo citar algunos de sus poemas y versos.

Mercedes Santa Cruz, Condesa de Merlín, desde 1840, en Cartas desde La Habana, en el número XIX describe al guajiro y dice a Sofía Gay: "... ¿̇no se sentiría usted feliz de poder conversar con un guajiro, producto singular de España y de la vida en el campo?" Y después le aclara: "Los guajiros y montoneros no se parecen en nada a los campesinos de ninguna parte." (https://www.ecured.cu/Guajiro, consultado el 6 de abril de 2017).

Durante el siglo XIX no se aprecia, en el empleo del término guajiro, rasgos despectivos, al contrario, los criterios líricos son loables. Se concuerda con Díaz Perera que "...en Cuba muchas veces la palabra guajiro adopta un giro casi peyorativo" (https://www.ecured.cu/Guajiro, consultado el 6 de

\footnotetext{
32 José Manuel Carbonell y Rivera: Evolución dela cultura cubana (1608-1927). Vol.II: La poesía lírica en Cuba. La Habana. Imprenta El siglo XX, 1928. p149.

33 Idem. p.23.

34 Juan Cristobal Nápoles Fajardo: Poesías Completas. Editorial Arte y Literatura. La Habana, 1974. p.64.

35 Idem. p.66.

$36 \quad$ Idem. p.115.

$37 \quad$ Idem. p.123.

$38 \quad$ Idem. p.214.
} 
abril de 2017), pero a juicio de estos investigadores, este giro comienza a emplearse durante el período de la República Neo-Colonial (1902-1958).

En la actualidad algunos intelectuales despojan al término guajiro de su profundo valor identitario, al señalar que procede del inglés, como plantea Rivero Ricardo, en el artículo Guajiro al Natural:

(...) las tropas norteamericanas llamaban a los veteranos de la guerra de independencia war hero. Las palabras significan héroe de la guerra, pero para el oído del cubano sonaba guajiro. Y como los veteranos se replegaron a los campos después del 98, se les empezó a llamar así a los campesinos. 39

Nada más alejado de la verdad que este criterio, como tantos otros similares que circulan por Internet. En defensa de la cubanía, los intelectuales deben valorar con extrema precaución términos que circulan en los medios de comunicación sin una base etimológica profunda que refleje su historia y su valor antropológico.

\section{CONCLUSIONES}

El término guajiro fue escrito de múltiples formas por los cronistas de Indias, a partir de vocablos indígenas cuya fonética no comprendían plenamente. A la vez este término tiene diverso origen etimológico y contenido semántico.

El referido término se aplica al campesino cubano a partir del siglo XVIII y tiene plena generalización en el siglo XIX. Guajiro expresa un modo de vida, cultura y psicología social y está estrechamente relacionado con las raíces de la nacionalidad del pueblo cubano. La utilización de una etimología extranjerizante para este término, conspira contra la identidad cultural cubana.

39 Rosana Rivero Ricardo: Guajiro al Natural. Periódico jahora! ÓRGANO OFICIAL DEL COMITÉ PROVINCIAL DEL PARTIDO EN HOLGUÍN. WwW.ahora.Cu. 1 de abril de 2017. P.3 


\section{REFERÊNCIAS}

DE LAS CASAS, B. Historia de las Indias. Editor M. Aguilar. Madrid, 1927, vol. 1, CaP. LXVII.

GREGORI, N. En prólogo al Diccionario provincial casi razonado de vozes y frases cubanas de Esteban Pichardo. Editorial de Ciencias Sociales, La Habana, 1985.

PICHARDO, E. Diccionario provincial casi razonado de vozes y frases cubanas de Esteban Pichardo. Editorial de Ciencias Sociales, La Habana, 1985.

Ortiz, F. Nuevo Catauro de Cubanismos. Editorial de Ciencias Sociales, La Habana, 1974.

BACHILLER Y MORALES, A. Cuba Primitiva, origen, Lenguas, Tradiciones e Historia de los Indios de las Antillas Mayores y Las Lucayas. Imprenta La Correspondencia de Cuba.

FÉLIX DE ARRATE, J. M. Llave del Nuevo Mundo Antemural de Las Indias Occidentales. La Habana descrita: Noticias de su fundación, aumentos y estados. Comisión Nacional Cubana de la UNESCO. La Habana, 1964.

TORRES CUEVAS, E. Historia de Cuba 1492-1898. Formación y liberación de la nación. Editorial Pueblo y Educación. La Habana, 2001.

CARBONELL Y RIVERA, J. M. Evolución dela cultura cubana (1608-1927). Vol.II: La poesía lírica en Cuba. La Habana. Imprenta El siglo XX, 1928.

RIVERO RICARDO, R. Guajiro al Natural. Periódico jahora! ÓRGANO OFICIAL DEL COMITÉ PROVINCIAL DEL PARTIDO EN HOLGUÍN. WWW.ahora.Cu. 1 de abril de 2017.

https://www.ecured.cu/Guajiro (consultado el 6 de abril de 2017) www.ahora.cu (consultado 3 de abril de 2017) 